Bull. Chem. Soc. Ethiop. 2004, 18(1), 81-90.

ISSN 1011-3924

Printed in Ethiopia

(c) 2004 Chemical Society of Ethiopia

\title{
MICRON-SIZED POLYMER PARTICLES FROM TANZANIAN CASHEW NUT SHELL LIQUID. PART I: PREPARATION, FUNCTIONALIZATION WITH CHLOROACETIC ACID AND UTILIZATION AS CATION EXCHANGE RESIN
}

\author{
O.O. Ilomo, Y.M.M. Makame* and L.L. Mkayula \\ Department of Chemistry, University of Dar es Salaam, P.O. Box 35061, Dar es Salaam, \\ Tanzania
}

(Received April 28, 2003)

\begin{abstract}
Micron-sized polymer particles (MSPP) were prepared by formaldehyde condensation polymerization of cashew nut shell liquid (CNSL) previously emulsified with sodium lauryl sulphate. The sizes of the MSPP were found to range from 0.1 to $4.4 \mu \mathrm{m}$. Increasing the emulsifier concentration had the effect of increasing the average particle size as well as the rate of polymerization. On the other hand, the polymerization rate decreased as the amount of the catalyst (sodium hydroxide) increased. The MSPP were also found to be insoluble and stable in many organic solvents and in some inorganic reagents. The average number of surface $\mathrm{OH}$ groups was found to be $2.29 \times 10^{18}$ per milligram of polymer particles. Micron-sized carboxylated cation exchange resins (MCCER) were obtained by treating MSPP with monochloroacetic acid in an alkaline medium. The MCCER were found to exchange up to about $86 \mathrm{mg}$ of calcium ion per gram of polymer at $30{ }^{\circ} \mathrm{C}$ while the MSPP could exchange up to only about $6 \mathrm{mg}$ of calcium ion per gram of polymer, at the same temperature. Compared to MSPP, the MCCER showed more than a thirteen-fold improvement in cation exchange capacity.
\end{abstract}

KEY WORDS: Micron-sized polymer particles, Cashew nut shell liquid, Polymer functionalization, Cation exchange resins

\section{INTRODUCTION}

The preparations of polymer materials by emulsion, suspension or solution polymerization and other techniques follow well-known procedures [1-3], which have been developed through many years of extensive research. Petrochemical and natural products are the principle sources of monomers used in polymerizations. While petrochemicals cannot be sustained as they become either expensive or highly depleted leading to economical and environmental problems, natural products are renewable. Thus, it is necessary for the polymer industry to look for renewable monomer sources and cashew nut shell liquid (CNSL) is one of the natural products that has both unsaturated hydrocarbon and phenols compounds [4] of which may serve as a supplement monomer resource in the polymer industry.

CNSL is branded as natural or technical depending on the method of extraction. The former is obtained by solvent extraction while the latter by thermal extraction. The CNSL has the following components, cardanol (1), cardol (2), 2-methylcardol (3) and anacardic acid (4) [5-9].<smiles>Oc1cccc(P)c1</smiles>

1<smiles>[R]c1cc(O)cc(O)c1</smiles>

2<smiles>[R]c1cc(O)c(C)c(O)c1</smiles>

3<smiles>[R]c1cccc(O)c1C(=O)O</smiles>

4
$\mathrm{R}=\mathrm{C}_{15} \mathrm{H}_{31-\mathrm{n}}$
$\mathrm{n}=0,2,4$ or 6

*Corresponding author. E-mail: makame@chem.udsm.ac.tz 
CNSL can take part in ether linkage, usually in an alkaline medium forming useful compounds such as ethyl ether cardanol (5) and cardanoxy acetic acid (6). These materials (5 and 6) have wide applications in the manufacture of paints, binders, varnishes and many others $[6,7]$.

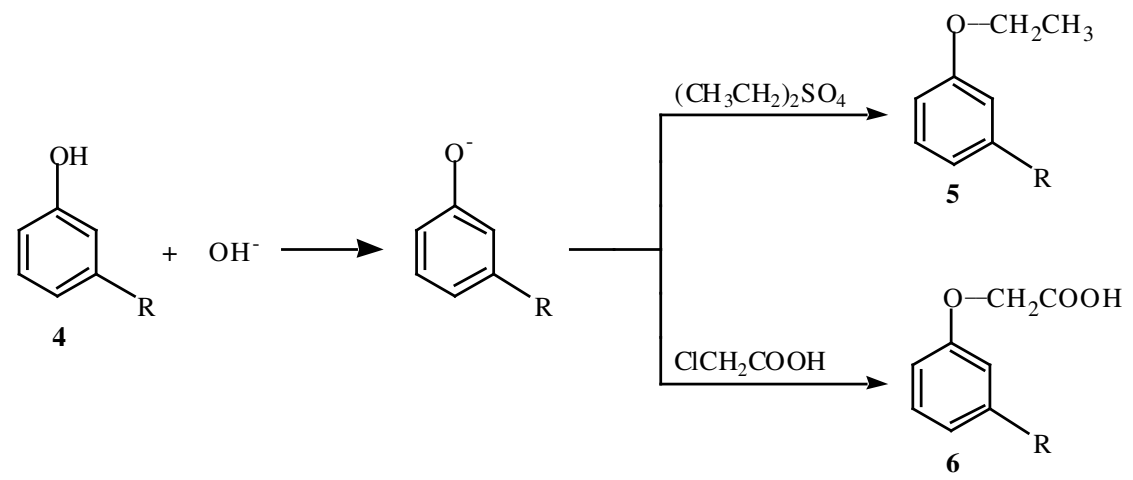

CNSL being phenol and having an unsaturated side chain may undergo polycondensation and addition polymerization reactions. In this work, a condensation polymerization reaction involving CNSL and formaldehyde was adopted.

Various applications of CNSL have been reported in some literature. These include; preparation of spherical polymer particles (SPP) for adsorption processes [8] and for immobilization of both yeast invertase and yeast cells [9], formulation of sisal reinforced composite [10] and preparation of polyurethane [4]. CNSL seems to be a promising potential resource in the polymer industry.

The use of phenol-formaldehyde polymeric materials for ion exchange applications are well documented $[6,7,11]$ and attempts to improve the ion exchange capacity of phenolic resins by suitable chemical treatment have also been reported. Micron-sized polymer particles (MSPP) from CNSL can be prepared by emulsion polycondensation of the monomer with formaldehyde; and these polymer particles, like other similar phenolic resins, could be widely used. By attaching appropriate functional groups onto the MSPP through a suitable surface modification reaction, CNSL based resin with improved ion exchange capacity for utilization in ion exchange processes could be obtained. Such CNSL-based resins are envisaged for wide applications in water purification and treatment of industrial effluents. Thus, this work reports the preparation of carboxylated micron-sized cation exchange resins from Tanzanian CNSL for possible application in ionic separation protocols.

\section{EXPERIMENTAL}

\section{Materials and reagents}

Cashew nut shell liquid was collected from TANITA cashew nut processing industry located in Dar es Salaam. Potassium and sodium hydroxides pellets (99\% purity) were supplied by Unilab while formalin $(37-41 \% \mathrm{w} / \mathrm{v})$, analytical grade sodium lauryl sulphate (NaLS), sulphuric acid, hydrochloric acid, nitric acid, $n$-hexane, cyclohexanol, cyclohexane, acetone, pet-ether, toluene, methanol, ethanol, chloroform, acetic acid, monochloroacetic acid and sodium acetate were supplied by BDH Chemicals Ltd. 
Determination of density and viscosity of CNSL

A Mettler AM100 analytical balance and a $10 \mathrm{~mL}$ specific density bottle were used. The specific density of CNSL was determined as the ratio of weight of a given volume $(10 \mathrm{~mL})$ of the sample to the weight of same volume of distilled water; the temperatures of both liquids were kept constant at $28{ }^{\circ} \mathrm{C}$. The viscosity of CNSL was determined using the Haake Viscotester VT 02 following a standard recommended procedure [12].

\section{Preparation of micron-sized polymeric particles (MSPP)}

Micron-sized polymeric particles of different sizes were prepared by condensation polymerization of CNSL with formaldehyde using different amount of $\mathrm{NaLS}$ and $\mathrm{NaOH}$. Polymerizations were carried out in a four-necked one-liter jacketed glass reactor equipped with a stainless stirrer, a reflux condenser and a thermometer. The reactor was heated by passing hot water from a thermostatic water-bath.

About $500 \mathrm{~g}$ of distilled water, about $30 \mathrm{~g}$ of CNSL, and variable amounts of sodium hydroxide and sodium lauryl sulphate (as in Table 1) were transferred into the reactor. The mixture was heated to $60{ }^{\circ} \mathrm{C}$ under constant stirring for one hour. About $16 \mathrm{~mL}$ of formalin were added to the mixture in the reactor to start polymerization while the temperature was maintained at about $60 .{ }^{\circ} \mathrm{C}$ for another hour, and then raised to about $80 .{ }^{\circ} \mathrm{C}$ till the end of the process. Constant stirring was maintained during the whole reaction time. Polymerization was complete in about four to six hours.

\section{Determination of percentage conversion}

The procedure used by Makame [13] was adopted with some modifications. The average rates of polymerization were obtained from the slopes of conversion versus time curves while the conversion at infinite time gave the yield [13].

A known weight of latex was withdrawn from the reactor after every 30 to 60 minutes. The sample was filtered and the residue was washed thoroughly initially with plenty of distilled water and finally with acetone. The residue was dried in an oven at $60{ }^{\circ} \mathrm{C}$ and then allowed to cool and weighed. The percentage conversion at time $\mathrm{t}$, was determined gravimetrically as:

$\%$ conversion $=\frac{\text { mass of polymer present in the sample at time } t}{\text { mass of polymer exp ected in the sample on completion of the reaction }} \times 100$

Preparation of MCCER: (Surface reaction with monochloroacetic acid)

The MSPP prepared above were treated with monochloroacetic acid to obtain the MCCER. A procedure described by Ault [14] was adopted with some minor modifications. $5 \mathrm{~g}$ of monochloroacetic acid was added to a mixture of $4 \mathrm{~g}$ of MSPP in $100 \mathrm{~mL}$ of $1.003 \mathrm{M} \mathrm{NaOH}$. The mixture was heated for about four hours on a steam bath. The $\mathrm{pH}$ of the mixture was carefully followed until a constant value was attained, indicating the completion of the reaction. The mixture was cooled to room temperature, washed with plenty of distilled water and filtered. The conductance and chloride free tests were simultaneously done to every $50 \mathrm{~mL}$ portion of the filtrate (or washings). The washing was stopped when the filtrate was free from chloride ions and the conductance of both the filtrate and the distilled water were equal. Thereafter, the particles (MCCER) were mixed with $100 \mathrm{~mL}$ of $1 \mathrm{M} \mathrm{HCl}$ and heated on a water-bath for about one hour while stirring. The washing and filtration cycles were repeated and finally the particles (MCCER) were dried in an oven at a temperature of $60^{\circ} \mathrm{C}$. 
Determination of cation exchange capacity

The ability of MSPP or MCCER to exchange calcium ions was determined by passing a solution containing calcium ions through a chromatographic column packed with a known weight of either MSPP or MCCER sample. The concentrations of calcium ions in the eluant and the effluent solutions were determined by conductometric titration using standard sodium carbonate solution and from their difference the amount of calcium exchanged was deduced.

\section{RESULTS AND DISCUSSION}

\section{The density and viscosity of CNSL}

Usually the viscosity and density of the monomer affect polymerization processes especially the polymerization rate and the size of the particles produced. The average density and viscosity of CNSL used in this work were found to be $0.976 \mathrm{~g} / \mathrm{mL}$ and 850 centipoises, respectively, at 28 ${ }^{\circ} \mathrm{C}$ and atmospheric pressure. The value of viscosity of CNSL differs from those reported by other workers. Mwalongo [8] had reported viscosity values of 627.17 and 1849.80 centipoises for CNSL samples obtained from Kibaha and Pugu, respectively, while Matechi [9] had reported a viscosity value of 334.7 centipoises for CNSL sample of undisclosed origin. Mwalongo [8] attributed the values of viscosities of CNSL to the lifetime of the samples. The CNSL samples having 627.17 and 1849.80 centipoises were six months and six years old, respectively [8], though both were thermally extracted. Other authors account for variation in viscosity of CNSL to be due to geographical factors maintaining that climate influences the biochemistry of the cashew nut [15]. For the density of CNSL, however, our results conform to earlier reported values of $0.96 \mathrm{~g} / \mathrm{mL}$ [9] and $0.95-0.97 \mathrm{~g} / \mathrm{mL}$ [8].

\section{Preparation of MSPP}

Preparation of MSPP through emulsion polycondensation of CNSL with formaldehyde in alkaline media was found to give good results when the concentration of NaLS in the reaction mixture was about or greater than 1.5 times the critical micelle concentration $(\mathrm{cmc})$. The approximate value for the critical micelle concentration of NaLS at the temperature of the reaction is $1.5 \mathrm{~g} / \mathrm{L}$ [16]. Coagulation was observed to be a severe problem for the recipes with NaLS concentrations less than 1.5 times the $\mathrm{cmc}$ value. This is probably due to the fact that at low emulsifier concentration $(<1.5$ times its $\mathrm{cmc})$ the stabilization of the monomer droplets as well as the solubilization of the monomer were very poor. Vanderhoff and van den Hul [17] and Sæthre [18] also reported similar observations for emulsion and minisuspension polymerization systems, respectively. The recipes and some results of the preparation of MSPP are shown in Table 1. The MSPP prepared were found to have narrow size distribution and particle sizes ranged from 0.1 to $4.4 \mu \mathrm{m}$ as shown in Table 1. Figures 1 and 2 show the TEM and the light micrographs of the polymer particles, respectively.

In classical emulsion polycondensation, the emulsion is formed merely by application of strong agitation and inorganic insoluble powdered salts [19] are used to stabilize the monomer droplets and the polymer particles against coalescence and coagulation. The size (diameter) of the resulting particles is of order of millimetres. In order to produce micron-sized particles, the technique was slightly modified by applying an emulsifier that functions as a more effective dispersant and monomer droplets' stabilizer. Thus the function of the emulsifier was two-fold to ease emulsification so as to yield micron-sized polymer particles (MSPP) and to enhance particle stabilization (electrostatic stabilization) as is the case in emulsion polymerization. 
Table 1. The recipes used in the preparation of MSPP: dependence of particle size and size distribution on the amount of the ingredients in the recipes.

\begin{tabular}{|cccccccc|}
\hline Recipe No. & CNSL/g & Formalin/g & NaLS/g & Water/g & NaOH/g & PSR/ $\mu \mathrm{m}$ & $\begin{array}{c}\text { Observatio } \\
\mathrm{n}\end{array}$ \\
\hline EC-16 & 30.883 & 16.434 & 4.443 & 500.70 & 1.097 & $1.4-4.4$ & C on Top \\
EC-01 & 30.140 & 16.025 & 1.114 & 500.21 & 1.015 & $0.7-3.1$ & Severe C \\
EC-02 & 30.164 & 16.003 & 2.222 & 500.11 & 1.014 & $0.3-1.9$ & $\mathrm{C}$ \\
EC-03 & 30.030 & 16.040 & 4.444 & 500.55 & 1.137 & $0.3-2.2$ & $\mathrm{C}$ \\
EC-07 & 30.055 & 16.036 & 4.446 & 500.36 & 0.197 & $0.1-3.0$ & No C/clean \\
EC-08 & 30.327 & 16.009 & 8.889 & 500.41 & 0.193 & $0.1-0.6$ & No C/clean \\
\hline
\end{tabular}

PSR and $\mathrm{C}$ stand for particle size range, and coagulation, respectively.

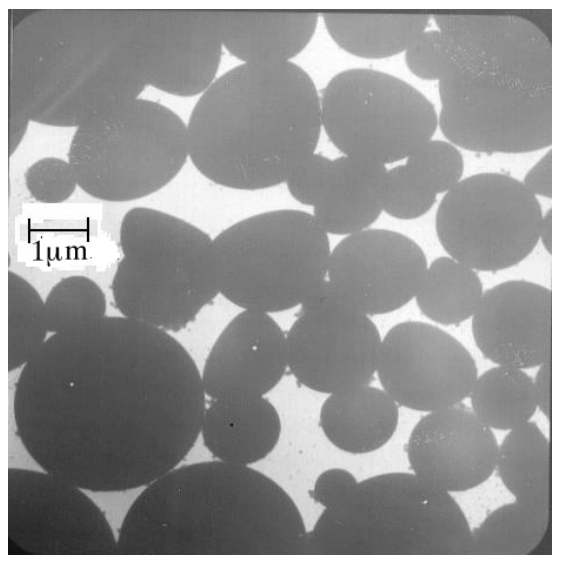

Figure 1. TEM micrograph of MSPP. Recipe EC-16.

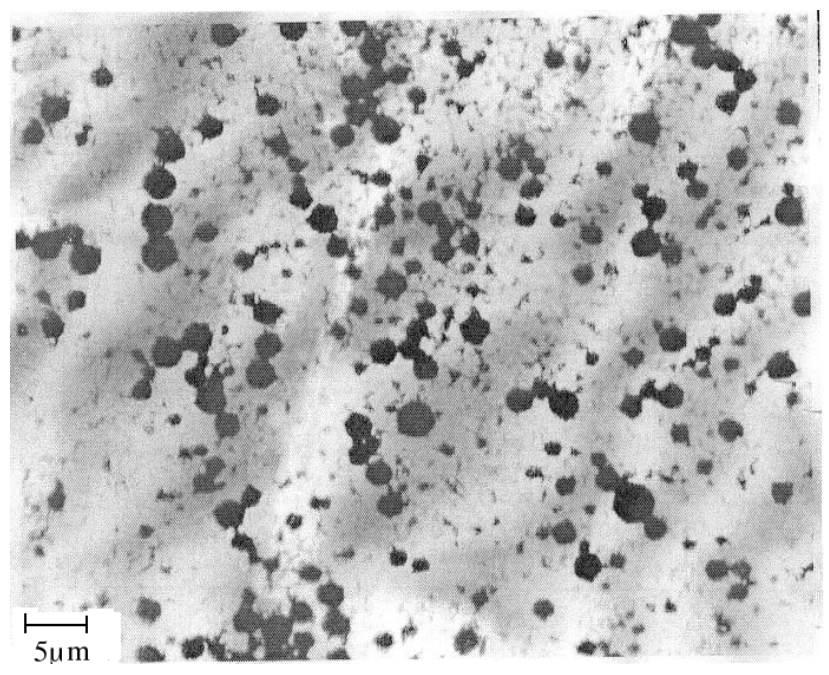

Figure 2. Light micrograph of MSPP. Recipe EC-07.

Bull. Chem. Soc. Ethiop. 2004, 18(1) 
Polymerization rate and polymer yield

Polymerization took about four hours and more than six hours for un-buffered and buffered systems, respectively. For un-buffered systems, the $\mathrm{pH}$ changed significantly from about 14 at the beginning down to 9 at the end of the polymerization process. The results are shown in Figure 3. These results suggest that maintaining constant acidity in the reaction mixture by buffering did significantly affect the polymerization rate. The initial polymerization rates were higher for the un-buffered reaction systems compared to the corresponding buffered reaction systems. Moreover buffering the reaction system did also affect the polymer yield attained. The yields attained by the un-buffered reaction mixtures were 20-30\% higher compared to the yields realized by the corresponding buffered systems. For the buffered systems, electrolytes such as sodium acetate and acetic acid were used as buffering agents. Elevated electrolyte concentrations are known to destabilize emulsion systems. The lower initial reaction rates observed for the buffered reaction systems could have resulted from the coalescence of the monomer droplets, which reduce the number of effective reaction loci. The lower yields in buffered systems compared to un-buffered ones are due to the electrolyte enhanced coagulation of latex particles during the sticky stage of polymerization [20]. Similar results have been reported elsewhere [21].

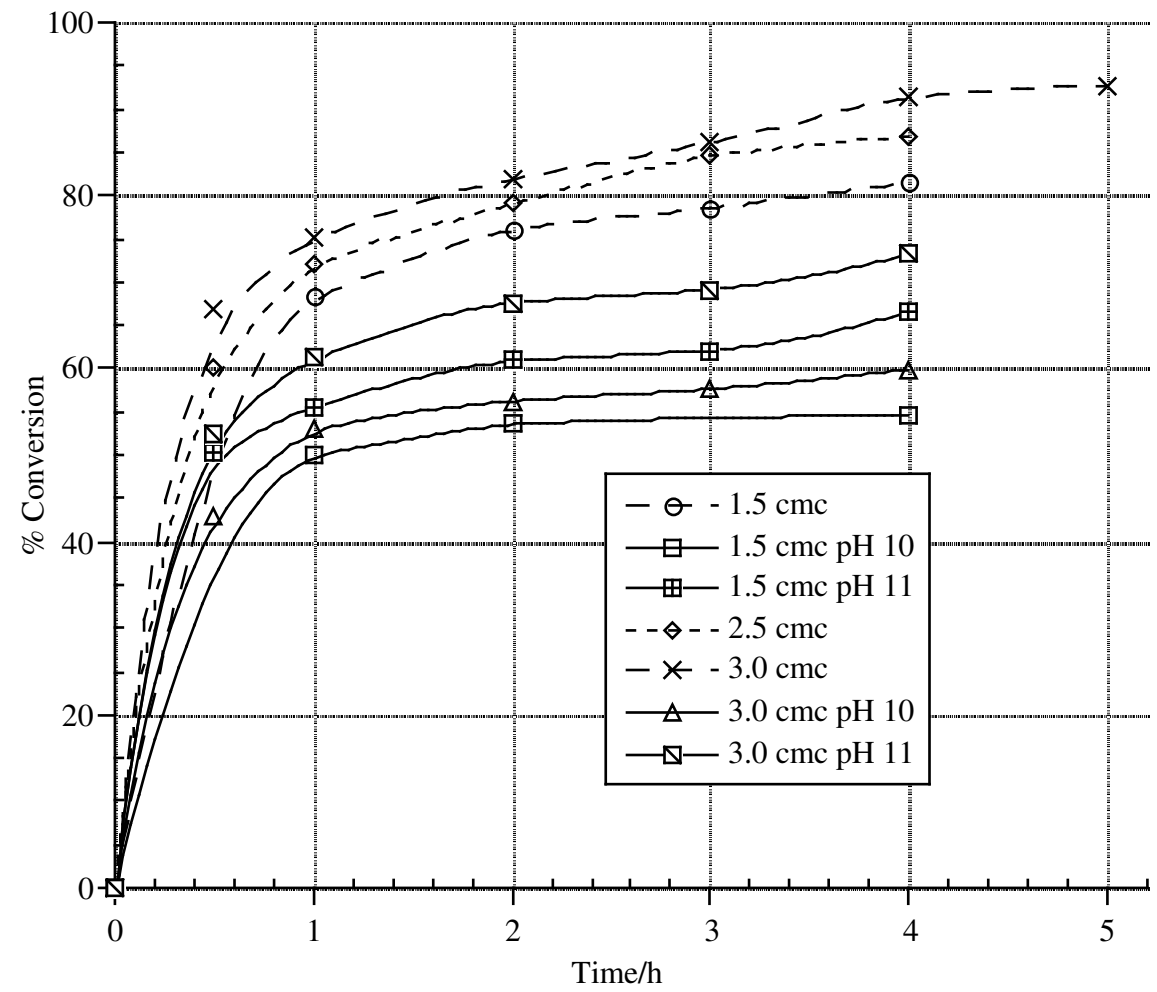

Figure 3. Effect of emulsifier (NaLS) concentration and $\mathrm{pH}$ on the rate of polymerization of CNSL with formaldehyde. Solid lines ( _ $)$; buffered reaction mixture. Dashed lines (....); un-buffered reaction mixture.

Bull. Chem. Soc. Ethiop. 2004, 18(1) 
In addition to $\mathrm{pH}$ dependence, the initial polymerization rate and the polymer yield were found to depend on the emulsifier concentration. Doubling the emulsifier concentration roughly doubled the initial polymerization rate for both buffered and un-buffered systems. This dependence of the initial polymerization rate on emulsifier concentration is in contrast to the situation in suspension polymerization processes where the concentrations of the stabilizers normally have very little influence on the polymerization rates. On the other hand doubling the emulsifier concentration increased the yield by about $10 \%$ for un-buffered systems and by about $5 \%$ for buffered systems as shown in Figure 3 at low emulsifier concentrations. In the first hour of polymerization the conversion was more than about $50 \%$, thereafter, conversion increased at a low rate of about $5 \%$ per hour. The increase in effective polymerization loci is probably the reason for the increase in the initial polymerization rate with the emulsifier concentration [20].

\section{Insolubility and chemical stability of the polymer particles}

When the MSPP were treated with various organic solvents, mineral acids and alkaline solutions they were found to be largely insoluble and maintained mechanical integrity as expected for three-dimensional crosslinked polymer materials. The observed insolubility and mechanical integrity of the particles strongly supports the possibility of utilizing the same for commercial ion exchange applications since ion exchange materials of practical importance must be practically insoluble in water and in organic solvents $[11,22]$.

\section{Surface hydroxyl groups of the MSPP and preparation of MCCER}

In addition to the physical and mechanical properties such as insolubility and hardness, the performance of ion exchange resin also depends on the concentration of surface ionic groups. The average number of surface $\mathrm{OH}$ groups of the MSPP was found to be $2.29 \times 10^{18} \mathrm{OH}$-groups per mg of polymer particle. This corresponds to about $4 \mathrm{mmol}$ replaceble hydrogen per $\mathrm{g}$ polymer, a value that is in the same order of magnitude as the cation exchange capacity of some commercially available carboxylated ion exchange resins [23]. Carboxylated cation exchange resins have been used for the separation of strong amino acids or organic bases from their weak counterparts [22]. Apart from separation of organic components, the resins could be used as a tool in water purification processes.

\section{Cation exchange capacity of MSPP and MCCER}

The results of Figure 4 show that the exchange capacities of MSPP and their MCCER counterparts for calcium ions were 6.57 and $86.36 \mathrm{mg}$ of calcium ion per gram of the polymer at $30{ }^{\circ} \mathrm{C}$, respectively. The results indicate that functionalization of MSPP to MCCER lead to about a thirteen-fold improvement in ion exchange capacity of CNSL based resin. Consequently, the results in Figures 4 and 5 show that the MCCER was not exhausted or saturated easily during calcium ion exchange process. This is a very important characteristic of any ion exchange resin [22]. 


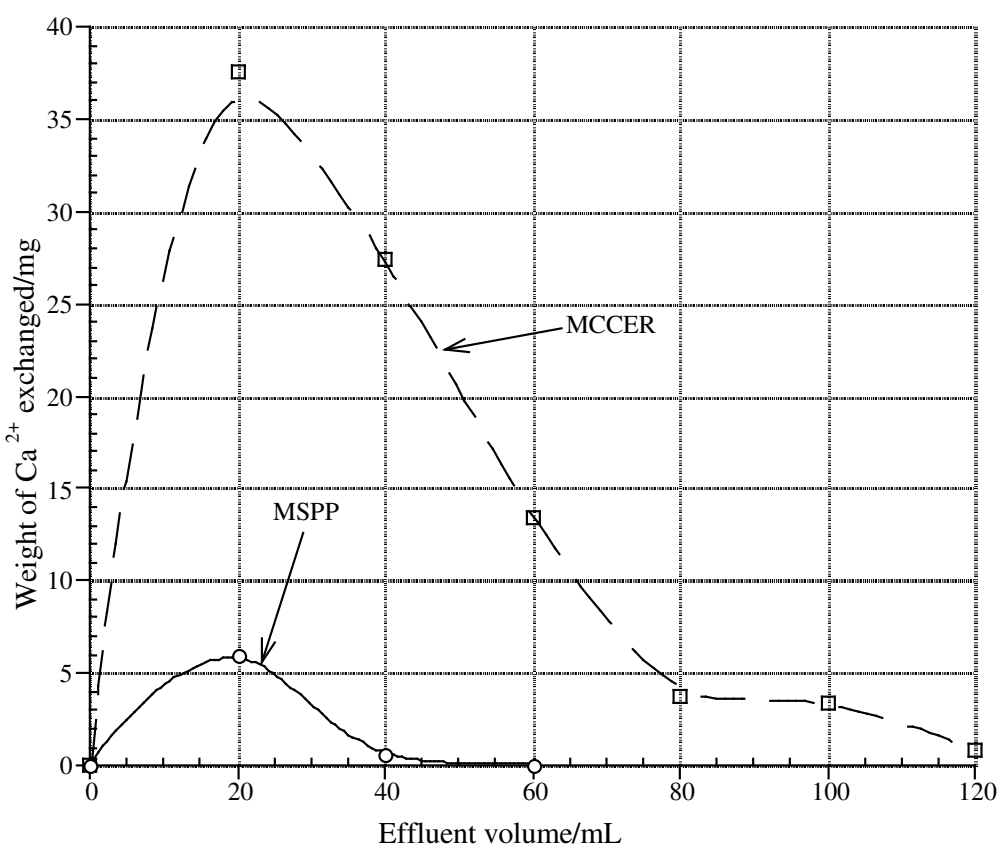

Figure 4. Cation exchange capabilities of the MSPP and MCCER.

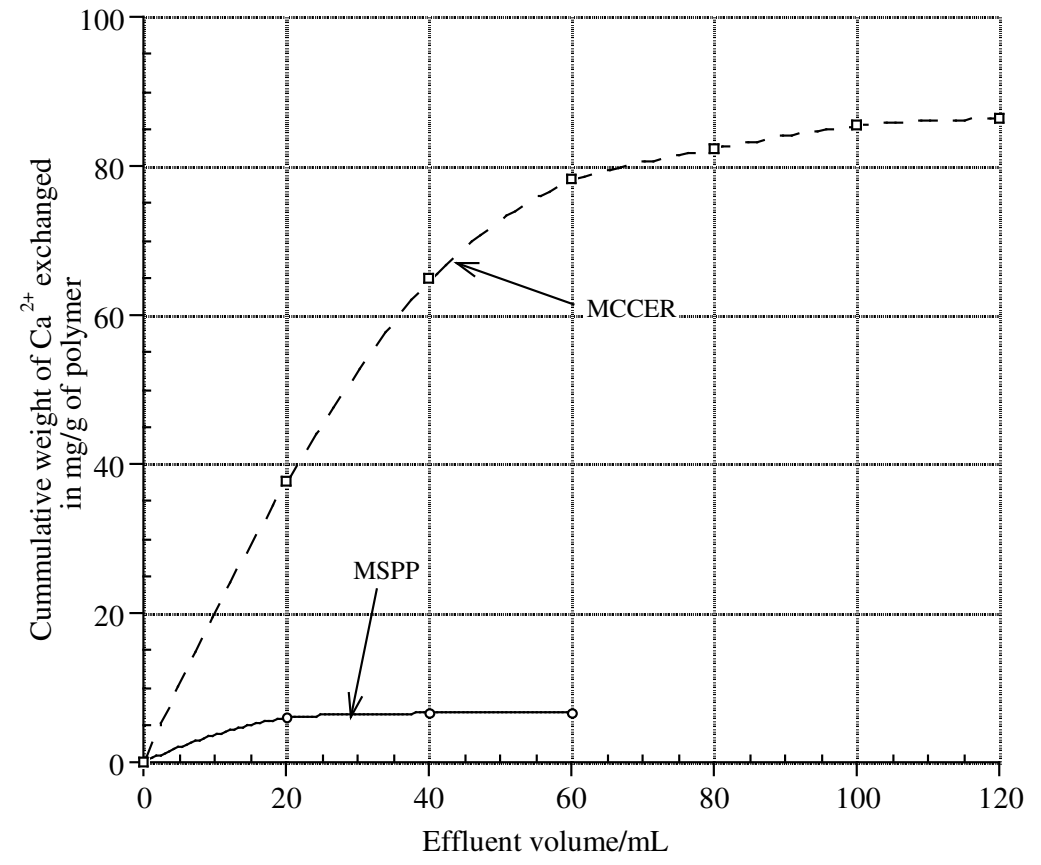

Figure 5. Cumulative cation exchange capabilities of MSPP and MCCER.

Bull. Chem. Soc. Ethiop. 2004, 18(1) 


\section{CONCLUSION}

The emulsion polycondensation technique has led to a successful preparation of MSPP of particle sizes ranging from 0.1 to $4.4 \mu \mathrm{m}$ having considerable chemical stability against various inorganic and organic reagents or solvents. The amounts of catalyst and emulsifier used affected both the polymerization rate and the yield. While increase in $[\mathrm{NaOH}]$ decreased the initial polymerization rate, increase in $[\mathrm{NaLS}]$ increased the initial rate. The average number of surface hydroxyl groups was found to be approx. $4 \mathrm{mmol} \mathrm{OH}$ groups per gram polymer. The MSPP was found to exchange about $6 \mathrm{mg}$ of $\mathrm{Ca}^{2+}$ per gram of polymer, while its derivatized MCCER counterpart exchanged about $86 \mathrm{mg}$ of $\mathrm{Ca}^{2+}$ per gram of polymer at $30^{\circ} \mathrm{C}$.

The results of this work suggest that the techniques used in the preparation of MCCER are suitable and if followed lead to products which may be used in various ion exchange processes. Further study is in progress to characterize the MSPP and MCCER prepared in this work.

\section{ACKNOWLEDGEMENTS}

We are grateful to the Norwegian Agency for Development Cooperation (NORAD), through the Chemistry Department, University of Dar es Salaam for financing this project. We also thank

the staff of Electron Microscope Unit of the University of Dar es Salaam for the technical assistance.

\section{REFERENCES}

1. Billmeyer, F.W. Textbook of Polymer Science, 3rd ed., John Wiley: New York; 1984.

2. Miles, D.C.; Briston, J.H. Polymer Technology, Temple Press: London; 1965.

3. Odin, G. Principles of Polymerization; 3rd ed., John Wiley: New York; 1991.

4. Bhunia, H.P.; Jana, R.N.; Basak, A.; Lenka, S.; Nando, G.B.; J. Polym. Sci. Part A: Polym. Chem. 1998, 36, 391.

5. Tyman, J.H.P. J. Chromatogr. 1975, 111, 285.

6. Gedam, P.H.; Sampathkumaran, P.S. Prog. Org. Coatings 1986, 14, 115.

7. Anand, L.C. Paintindia 1978, 28, 13.

8. Mwalongo, G.C.J. M.Sc. Thesis, University of Dar es Salaam, Tanzania, 1997.

9. Matechi, T.M. M.Sc. Thesis, University of Dar es Salaam, Tanzania, 1995.

10. Bisanda, E.T.N.; Ansell, M.P. J. Materials Sci. 1992, 27, 690.

11. Kunin, R. Ion Exchange Resin, John Wiley: New York; 1963.

12. HAAKE, Instruction Manual - Viscotester VT01/VT02, Karlsruhe, 1987.

13. Makame, Y.M.M. Ph.D. Thesis, Norwegian University of Science and Technology, Trondheim, Norway, 1997.

14. Ault, A. Techniques and Experiments for Organic Chemistry, Allyn and Bacon Inc: Boston; 1987.

15. Kapoor, V.P; Farooqi, M.I.H.; Tavavel, F.R.; Joseleau, J.P. Carbohyr. Res. 1991, 222, 289.

16. Hansen, F.K.; Ugelstad, J. J. Polym. Sci.: Polym. Chem. ed. 1979, 3069.

17. Vanderhoff, J.W.; Van Den Hul, H.J. J. Colloid Interface Sci. 1968, 28, 336.

18. Sæthre, B. Ph.D. Thesis, University of Trondheim, Norway, 1994.

19. Sokolov, L.B. Synthesis of Polymers, Israel Program for Scientific Translation Ltd.: Jerusalem; 1968.

20. Blackley, D.C. Emulsion Polymerization, A.S.P. Ltd.: London; 1975.

21. Brouwer, W.M. J. Appl. Polym. Sci. 1989, 38, 1335. 
22. Samuelson. O. Ion Exchange Separation in Analytical Chemistry, Almqvist and Wiksell: Stockholm; 1963

23. Mark, H.F.; Bikales, N.M.; Overberger, C.G.; Menges, G. Encyclopedia of Polymer Science and Engineering, Vol. 8, 2nd ed., John Wiley: New York; 1985. 